\title{
Malposition of Central Venous Catheter due to Radiation-Induced Venous Stenosis: A Report
}

Sir,

The article by Venugopal et al. made for an interesting reading and an informative case series. ${ }^{[1]}$ We agree with their conclusion that chest X-ray (CXR) is the gold standard and should be routinely practiced for identifying central venous catheter (CVC) malposition. We would like to report one such case in which we encountered malposition of CVC due to radiation-induced venous stenosis. After an extensive search, we did not find any case of radiation-induced CVC malposition reported. Radiotherapy (RT) may cause distortion of airway anatomy along with edema, swelling of the tissues, osteoradionecrosis, and stenosis or occlusion of the major vessels. $^{[2]}$

A 56-year-old female weighing $55 \mathrm{~kg}$ was admitted with the complaints of dysphagia and weight loss. She was diagnosed with carcinoma of the larynx, pharynx, with infiltration of the upper esophagus 8 months prior, and was posted for total pharyngo-laryngo-oesophagectomy. She had undergone 2 cycles of chemotherapy and 30 cycles of RT (45 Gy) for the same, with no relief of symptoms. The day before surgery, using the standard Seldinger technique with portable ultrasound (ACUSON, Siemens) guidance, the right subclavian vein (SV) was cannulated with 7 Fr triple-lumen central venous pressure catheter (arrow) under all aseptic precautions. All the three ports of CVC were aspirated for blood and fixed at $13 \mathrm{~cm}$. CXR was done postinsertion to confirm the position of CVC, which revealed that the tip of the catheter was in the right internal jugular vein (IJV) [Figure 1]. The catheter was withdrawn and reinserted correctly through the right IJV.

Head-and-neck malignancy cases presenting for surgery, either primarily or subsequent to RT and chemotherapy, are common. RT has been extensively used as an adjuvant therapy

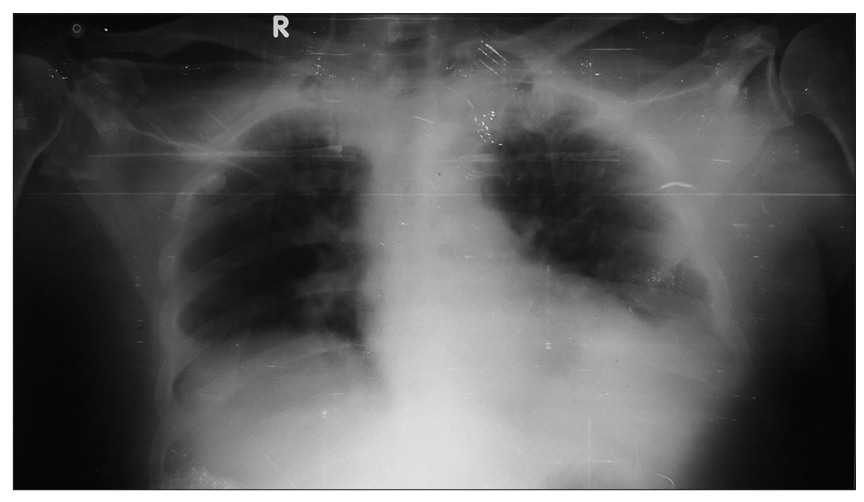

Figure 1: Chest X-ray showing central venous catheter inserted in the right subclavian vein, tip positioned in the right internal jugular vein for malignancies. This case is unique as radiation-induced venous stenosis is extremely rare, and we found it only in a few published reports. ${ }^{[3,4]}$ We aim to report this case, although rare, but the possibility of radiation-induced venous stenosis which leads to malposition of CVC exists in patients with malignancies who had undergone multiple episodes of radiation. Aspiration of blood does not confirm the correct placement of CVC. Ultrasound (USG) decreases the failure rate, but USG can give localization of entry points of needle and guidewire position but not the catheter tip. It was found that the guidewire placed in the right SV proceeded along the right brachiocephalic vein (BCV) and then, instead of proceeding caudad toward the right atrium, turned toward the right IJV and, due to the stenosis at the left BCV [Figure 2], the tip of the guidewire deflected toward the right IJV. CVC cannulation by the right $\mathrm{SV}$ was associated with the highest risk of malposition $(9.1 \%)$ than that of right IJV (1.4\%). We kept the direction of the J-tip of the guidewire caudad to avoid the unusual pathway as we know that the direction of the J-tip of the guidewire may get deflected by an obstruction during its insertion and stenosis may contribute to the malposition of the CVC. ${ }^{[5]}$ We would like to concur with the authors that CVC insertion should be with electrocardiography monitoring guidance as it detects intracardiac placement quickly.

\section{Declaration of patient consent}

The authors certify that they have obtained all appropriate patient consent forms. In the form the patient(s) has/have given his/her/their consent for his/her/their images and other clinical information to be reported in the journal. The patients

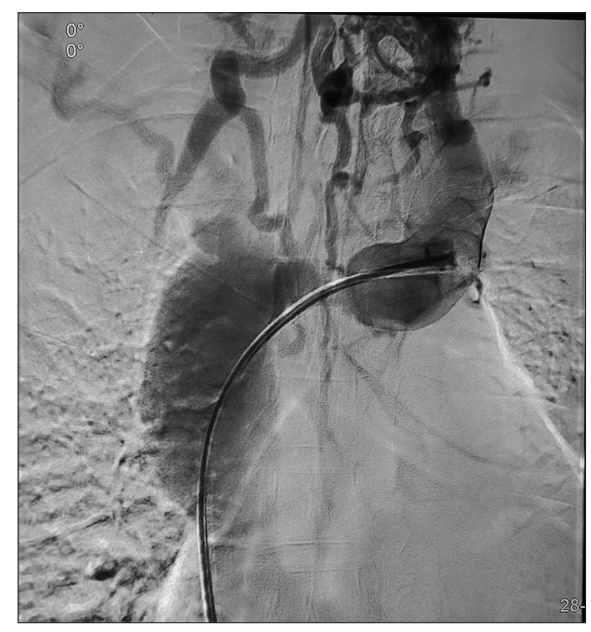

Figure 2: Digital subtraction angiography showing stenosis at the left brachiocephalic vein 
understand that their names and initials will not be published and due efforts will be made to conceal their identity, but anonymity cannot be guaranteed.

\section{Financial support and sponsorship \\ Nil.}

\section{Conflicts of interest}

There are no conflicts of interest.

Jay Prakash, Radhika Dhanpal, Natesh S. Rao, Sarayu Ramamurthy Department of Anaesthesia and Critical Care Medicine, Vydehi Institute of Medical Sciences and Research Centre, Bengaluru, Karnataka, India

Address for correspondence: Dr. Jay Prakash, 205, Roma Pearl Apartment, AECS Layout A-Block, Kundalahalli, Bengaluru - 560 037, Karnataka, India. E-mail:dr.jay_prakash@rediffmail.com

\section{RefERENCES}

1. Venugopal AN, Koshy RC, Koshy SM. Role of chest X-ray in citing central venous catheter tip: A few case reports with a brief review of the literature. J Anaesthesiol Clin Pharmacol 2013;29:397-400.

2. van Putten JW, Schlosser NJ, Vujaskovic Z, Leest AH, Groen HJ. Superior vena cava obstruction caused by radiation induced venous fibrosis. Thorax 2000;55:245-6.
3. Zhou W, Bush RL, Lin PH, Lumsden AB. Radiation-associated venous stenosis: Endovascular treatment options. J Vasc Surg 2004;40:179-82.

4. Girinsky T. Effects of ionizing radiation on the blood vessel wall. J Mal Vasc 2000;25:321-4.

5. Dubey PK. Central venous catheter misplacement and the guidewire. J Anaesthesiol Clin Pharmacol 2016;32:406-7.

This is an open access journal, and articles are distributed under the terms of the Creative Commons Attribution-NonCommercial-ShareAlike 4.0 License, which allows others to remix, tweak, and build upon the work non-commercially, as long as appropriate credit is given and the new creations are licensed under the identical terms.

\begin{tabular}{|l|l|}
\hline \multicolumn{3}{|c|}{ Access this article online } \\
\hline Quick Response Code: & Website: \\
& www.ijccm.org \\
& \\
\end{tabular}

How to cite this article: Prakash J, Dhanpal R, Rao NS, Ramamurthy S. Malposition of central venous catheter due to radiation-induced venous stenosis: A report. Indian J Crit Care Med 2018;22:314-5.

(C) 2018 Indian Journal of Critical Care Medicine | Published by Wolters Kluwer - Medknow 